\title{
Correction to: Semi-autonomous Vehicle Transmission and Braking Systems
}

\author{
G. Paul Robertson and A. Rammohan
}

\section{Correction to:}

Chapter "Semi-autonomous Vehicle Transmission and Braking Systems" in: M. R. Nalim et al. (eds.), Advances in Automotive Technologies, Lecture Notes in Mechanical Engineering, https://doi.org/10.1007/978-981-15-5947-1_4

In the original version of chapter "Semi-autonomous Vehicle Transmission and Braking Systems", the following belated corrections have been incorporated:

The author name "Rammohan A." has been changed to "A. Rammohan". The chapter and book have been updated with this change. 